\title{
Photosystem photochemistry, prompt and delayed fluorescence, photosynthetic responses and electron flow in tobacco under drought and salt stress
}

\author{
K. KHATRI ${ }^{*, * *}$ and M.S. RATHORE $E^{*, * *+}$ \\ Biotechnology and Phycology Division, CSIR-Central Salt and Marine Chemicals Research Institute \\ (CSIR-CSMCRI), Council of Scientific and Industrial Research (CSIR), Bhavnagar (Gujarat- 364001), India* \\ Academy of Scientific and Innovative Research, CSIR, New Delhi, India**
}

\begin{abstract}
The present study aimed to understand the photosynthetic responses and chlorophyll fluorescence transient in tobacco under drought and salt stress. Net $\mathrm{CO}_{2}$ assimilation rate, stomatal conductance, intercellular $\mathrm{CO}_{2}$ concentration and transpiration rate decreased significantly under drought and salt stress. The maximum quantum efficiency of PSII and electron transport rate were lower in tobacco under drought and salt stress. The maximum carboxylation rate, maximum electron transport rate, triosephosphate utilization efficiency, and mesophyll conductance decreased under drought and salt stress, while dark respiration increased. A pool size of the electron acceptors on reducing side of PSII and activity of water-splitting complex on the donor side of the PSII decreased during drought and salt stress. Present results suggested upregulation of the photorespiratory pathway as a strategy to maintain the ribulose-1,5-bisphosphate regeneration for maintenance of photosynthesis under drought and salt stress. Chlorophyll fluorescence indicated the impaired electron transfer and changes in the architecture of light-harvesting complex in tobacco leaves under drought and salt stress.
\end{abstract}

Additional key words: multisignal fluorescence; nonphotochemical quenching; photochemistry; photosynthetic performance; photorespiration.

\section{Introduction}

Photosynthesis is one of the key processes for existence of life. Plants under in vivo conditions are exposed to different kinds of stresses, e.g., light, drought, salinity, temperature, etc. These stresses negatively affect the photosynthesis through imposing the oxidative stress. Plants modulate their biochemical composition and physiology in order to adapt to prevailing environmental conditions. The most common environmental stresses are salt and drought stress. Both are interrelated as the salt stress is a kind of physiological drought. The molecular pathways leading to plant's adaptation under these two stresses overlap in various aspects. Under saline and drought conditions, an increased solute potential minimizes the stressinduced toxicity and maintains water contents and ionic homeostasis for optimal physiology. Plants conserve water by increasing water absorption or decreasing water loss through stomata (Thomas and Gausling 2000). Under such situation, the stomatal conductance $\left(g_{\mathrm{s}}\right)$ must decrease thereby reducing the photosynthetic gas exchange. The stomatal closure further reduces the cooling procedure and this causes accumulation of heat. Under such conditions, with limited $\mathrm{CO}_{2}$ assimilation, the water-water cycle cannot eliminate excess excitation energy by acting as a major alternative electron sink (Driever and Baker 2011). Further, under low $\mathrm{CO}_{2}$ concentration, the Rubisco causes increased oxygenation of ribulose-1,5-bisphosphate (RuBP) and higher Rubisco contents accelerate the rate of oxygenation. On the other hand, available light energy continuously induces electron transport which might lead to photoinhibition. The RuBP oxygenation produces one molecule each of glycolate-2-phosphate and glycerate-3-phosphate. The glycerate-3-phosphate

$\overline{\text { Received }} 16$ June 2017, accepted 20 July 2018.

${ }^{+}$Corresponding author; e-mail: mangalrathore@csmcri.res.in, mangalrathore@gmail.com.

Abbreviations: $\mathrm{Chl}$ - chlorophyll; $C_{\mathrm{i}}-$ intercellular $\mathrm{CO}_{2}$ concentration; Car - carotenoids; DAB - 3,3-diaminobenzidine; DM - dry mass; $E$ - transpiration rate; ETR - electron transport rate; FM - fresh mass; $g_{\mathrm{m}}-$ mesophyll conductance; $g_{\mathrm{s}}-$ stomatal conductance; $J_{0}$ - oxygenation; $J_{\mathrm{C}}$ - electron flow through PSII to RuBP carboxylation; $J_{\max }-$ maximum electron transport rate/electron transport capacity; NBT - nitroblue tetrazolium; NPQ - nonphotochemical quenching; PEG - polyethylene glycol; $\Phi_{\mathrm{PSII}}-$ efficiency of PSII; $P_{\mathrm{N}}$ - net $\mathrm{CO}_{2}$ assimilation rate; $P_{\mathrm{N}}-C_{\mathrm{i}}-\mathrm{CO}_{2}$-response curve; $\mathrm{q}_{\mathrm{P}}-$ photochemical quenching; $R_{\mathrm{D}}-$ dark respiration; $\mathrm{RH}-$ relative humidity; RuBP - ribulose-1,5-bisphosphate; TM - turgid mass; TPU - triosephosphate utilization; $V_{\text {cmax }}$ - maximum carboxylation rate; WUE - water-use efficiency.

Acknowledgment: Authors thankfully acknowledge the CSIR, Govt. of India for financial support (OLP0079). Ms. Khatri is thankful to Council of Scientific and Industrial Research, New Delhi for financial support in the form of Junior Research Fellow. CSIR-CSMCRI PRIS 078/2017. 
enters into the Calvin cycle and glycolate-2-phosphate, which act as chloroplast inhibitor, has to be converted into glycerate-3-phosphate. It was hypothesized that under stress conditions, plants manage optimum photosynthesis through altering their photorespiration and accelerating the RuBP regeneration (Huang et al. 2014).

The physiological alterations along with morphological modifications allow plants to cope with a broad range of environmental stresses. Photosynthetic measurements are important tounderstand the physiologicalresponses of plants under different stress conditions. Various environmental stresses are known to lower down the photosynthesis in plants. The simultaneous gas-exchange and fluorescence measurement are commonly used in plant stress analysis (Ashraf and Harris 2013). The simultaneous measurement of gas exchange and fluorescence indicate the net $\mathrm{CO}_{2}$ assimilation rate $\left(P_{\mathrm{N}}\right)$, intercellular $\mathrm{CO}_{2}$ concentration $\left(C_{\mathrm{i}}\right)$, mesophyll conductance $\left(g_{\mathrm{m}}\right)$, transpiration rate $(E)$, efficiency of PSII $\left(\Phi_{\text {PSII }}\right)$, photochemical quenching $\left(q_{\mathrm{p}}\right)$ and nonphotochemical quenching (NPQ), electron transport, and PSII photochemistry. Further, the $\mathrm{CO}_{2}$-response curve $\left(P_{\mathrm{N}}-C_{\mathrm{i}}\right.$; the photosynthentic rate plotted against intercellular $\mathrm{CO}_{2}$ concentration) and light-response curve (the photosynthetic rate plotted against light intensity) help figure out the maximum carboxylation rate, triosephosphate utilization, day respiration, mesophyll conductance, rate of photosynthetic electron transport supporting $\mathrm{NADP}^{+}$ reduction for RuBP regeneration, electron flow through PSII to RuBP carboxylation and oxygenation (Huang et al. 2014). These parameters indicate the physiological health of the plant and are used to assess the tolerance or adaptation under stress conditions.

The applications of chlorophyll (Chl) fluorescence are widely used in plant stress analysis (Kalaji et al. 2014, 2016 Lazár 2015). The antenna Chl of PSII is a source of variable fluorescence and $\mathrm{Chl} a$ fluorescence measurement is being widely used for screening of stress tolerance in different plant species. The concepts and scientific insights related to $\mathrm{Chl}$ fluorescence measurements perceived new parameters for plant stress analysis. This resulted in development of new techniques and new commercial instruments (Salvatori et al. 2014) for simultaneous measurement of prompt (PF) and delayed fluorescence (DF) and modulated reflectance of P700 (Strasser et al. 2010, Kalaji et al. 2012). The PF is the fluorescence induction curve from minimum $\left(\mathrm{F}_{0}\right)$ to maximum $\left(\mathrm{F}_{\mathrm{m}}\right)$ fluorescence in dark-adapted samples. The curve is known as fluorescence transient (FT) and represents the fast kinetics of fluorescence emission (Strasser et al. 2010); its normalized analysis is called JIP-test (Strasser et al. 2004). The OJIP transient reflects the kinetic properties of the electron transport chain and provides information on the redox states of PSII and efficiencies of electron transfer during photosynthetic electron transport chain. The DF occurs after PF decay, and it is a form of light emitted by plants mainly from PSII (Krasteva et al. 2013) in the red-infrared region once they are exposed to light. The DF occurs after electrons transfer backward in the photosynthetic chain and reflect the recombination between the reduced electron acceptor $\mathrm{Q}_{\mathrm{A}}{ }^{-}$and the oxidized secondary electron donor $\mathrm{Z}^{+}$of PSII (Salvatori et al. 2014). Measurements of prompt and delayed Chl $a$ fluorescence have been used to investigate photosynthesis under abiotic stress conditions, i.e., PSII electron donor side, electron transport between PSII and PSI, and PSI electron acceptor side (Strasser et al. 2010, Oukarroum et al. 2013, 2016; Gao et al. 2014). Protection of PSII and PSI photochemistry under drought stress through adjustment of the energy distribution between photosystems and activation of alternative electron sinks has been reported by Chl fluorescence measurement (Zivcak et al. 2013). Recent literature reports showed changes in PSII quality and functioning under different kinds of stresses (Kalaji et al. 2016). Drought stress inhibits reoxidation of $\mathrm{Q}_{\mathrm{A}}^{-}$and suppresses the quantum yields of photoinduced electron transport in PSII reaction center to $\mathrm{Q}_{\mathrm{A}}$ (Goltsev et al. 2012). Salinity stress has been reported to cause more damage on the donor side of PSII as compared to the acceptor side (Mehta et al. 2010).

During exposure of plants to stress conditions, the early responses are of critical significance. The early responses of the photosynthetic apparatus in plants play an important role in their tolerance to salt stress (Kalaji et al. 2011). In this work, we used infrared gas analyzer (LI-6400XT; Li-Cor, Lincoln, NE, USA) and multifunctional plant efficiency analyzer (MPEA-2; Hansatech Instruments, $\mathrm{UK})$ to understand the photosynthetic responses and Chl fluorescence transient in tobacco subjected to salt and drought stress for a short (24-h) duration. The aim of this study was to understand photosystem photochemistry, PF, DF, photosynthetic responses, light and $P_{\mathrm{N}}-C_{\mathrm{i}}$ response curve, and electron flow through photosynthetic and photorespiratory pathway during photosynthesis in tobacco under drought and salt stress. The results would be useful to understand the photosynthetic performance of plants under stress conditions. Further, the results would establish a linkage between photorespiration and photosynthesis in plants under stress conditions. The results would add some knowledge to our understanding of photosynthetic responses in a model plant, i.e., tobacco under salt and drought stress, which would serve as a base for functional validation of salt and drought-responsive genes. The results on a model plant could be easily used as a ready-made reference by the researcher for interpretation of results on functional validations of transgenic tobacco for the development of drought and salt tolerance.

\section{Material and methods}

Seed germination, plant growth, and stress treatments: The seeds of tobacco (Nicotiana tobacum L., cv. Petit Havana) were germinated and grown on $1 / 2$ strength of hormone-free $0.7 \%$ agar-gelled Murashige and Skoog's (MS) basal medium (Murashige and Skoog 1962) for two weeks in a culture room under 12-h photoperiod at PPFD of $150 \mu \mathrm{mol}$ (photon) $\mathrm{m}^{-2} \mathrm{~s}^{-1}, 25 \pm 1^{\circ} \mathrm{C}$, and $60 \%$ relative humidity $(\mathrm{RH})$. Two weeks-old seedlings were cultured hydroponically in the $1 / 2$ strength of Hoagland salt (without any chloride salt solution). These were grown for six weeks in a growth chamber (PGC-105, Percival Scientific, USA) 
at $25 \pm 1{ }^{\circ} \mathrm{C}, 60 \% \mathrm{RH}$, ambient $\mathrm{CO}_{2}$ concentration, and 12 -h photoperiod with a light intensity of $1,000 \mu \mathrm{mol}$ (photon) $\mathrm{m}^{-2} \mathrm{~s}^{-1}$. The six weeks-old plants $(n=3)$ were subjected to drought [5 and 10\% solution of polyethylene glycol-6000 (PEG-6000, Hi-Media, India)], and salt [0.1 and $0.2 \mathrm{M}$ solution of sodium chloride ( $\mathrm{NaCl}, \mathrm{Hi}$-Media, India)] stress individually for $24 \mathrm{~h}$ and the photosynthetic responses were recorded. After stress treatments, the samples were harvested, and physio-chemical analysis was carried out.

Determination of solute potential, relative water contents, and photosynthetic pigments: Leaf samples from control and stressed plants were frozen in liquid nitrogen, thawed, and centrifuged for $10 \mathrm{~min}$ at $10,000 \times \mathrm{g}$ to obtain the sap. Solute potential $(\Psi)$ of the sap was measured by vapor pressure osmometer (Wescor Inc., Logan, UT, USA).

Leaf discs of approximately $200 \mathrm{mg}$ fresh mass (FM) from control and treated plants were immersed in the deionized water for $18 \mathrm{~h}$, and the turgid mass (TM) were recorded. Samples were dried at $80^{\circ} \mathrm{C}$ for $48 \mathrm{~h}$ in a hot air oven, and the dry mass (DM) was recorded. Relative water content (RWC, \%) was calculated as (FM - DM)/ $(\mathrm{TM}-\mathrm{DM}) \times 100$.

Photosynthetic pigments were extracted in chilled $\mathrm{N}$, $\mathrm{N}$-dimethylformamide and the absorption was recorded at 461, 647, 664, and $664.5 \mathrm{~nm}$ using a UV-Visible spectrophotometer (SpectramaxPlus 384, Molecular Devices, USA). Chl contents were calculated following Inskeep and Bloom (1985), and the carotenoids (Car) were calculated following Chamovitz et al. (1993).

Light- and $\mathrm{CO}_{2}$-response curve: Plants were exposed to PPFD of 1,200 $\mu \mathrm{mol}$ (photon) $\mathrm{m}^{-2} \mathrm{~s}^{-1} \mathrm{~s}$ and $380 \mu \mathrm{mol}\left(\mathrm{CO}_{2}\right)$ $\mathrm{mol}^{-1}$ for $45 \mathrm{~min}$ to obtain a steady state before generating light- and $\mathrm{CO}_{2}$-response curves. The light-response curve was generated using an auto-program feature of the infrared gas analyzer (IRGA) system at an ambient $\mathrm{CO}_{2}$ concentration [set at $380 \mu \mathrm{mol}\left(\mathrm{CO}_{2}\right) \mathrm{mol}^{-1}$ using mixer facility of the instrument). The parameters of lightresponse curve were assessed stepwise at every $2 \mathrm{~min}$ at 2,$500 ; 2,000 ; 1,600 ; 1,200 ; 800,600,400,200,100,50$, 20 , and $0 \mu \mathrm{mol}$ (photon) $\mathrm{m}^{-2} \mathrm{~s}^{-1}$. $\mathrm{CO}_{2}$-response curve was generated using an auto-program feature of the IRGA system at PPFD of 1,200 $\mu \mathrm{mol}$ (photon) $\mathrm{m}^{-2} \mathrm{~s}^{-1}$. The parameters of $\mathrm{CO}_{2}$-response curve were assessed stepwise at every $3 \mathrm{~min}$ at 400, 300, 200, 100, 50, 500, 600, 800; 1,$000 ; 1,400 ; 1,800 ; 2,000$; and $2,200 \mu \mathrm{mol} \mathrm{mol}{ }^{-1}$. The light and $P_{\mathrm{N}}-C_{\mathrm{i}}$ response curves were fitted using curve fitting facilities (Sharkey et al. 2007, Sharkey 2016) and the maximum carboxylation rate $\left(V_{\mathrm{cmax}}\right)$, maximum electron transport rate $\left(J_{\max }\right)$ triosephosphate utilization (TPU), day respiration $\left(R_{\mathrm{D}}\right)$ mesophyll conductance $\left(g_{\mathrm{m}}\right)$ Rubisco content, electron flow through PSII to RuBP carboxylation $\left(J_{\mathrm{C}}\right)$ and oxygenation $\left(J_{0}\right)$ were determined.

Gas exchange and pulse modulated $\mathrm{Chl}$ fluorescence were measured simultaneously using a leaf chamber fluorometer (6400-40 LCF, $\mathrm{Li}$-Cor, USA) attached to an infrared gas analyzer (LI-6400XT; Li-Cor, Lincoln, NE, USA). Plants were dark-adapted for 45 min using dark facilities. The minimal fluorescence level $\left(\mathrm{F}_{0}\right)$ in the darkadapted state was measured using a modulated pulse, while maximal fluorescence $\left(\mathrm{F}_{\mathrm{m}}\right)$ was measured after applying a saturating actinic light. Steady-state fluorescence yield $\left(F_{s}\right)$ and maximum fluorescence yield $\left(F_{m}{ }^{\prime}\right)$ were recorded using saturating actinic light pulse after adapting plants to PPFD of $1,200 \mu \mathrm{mol}$ (photon) $\mathrm{m}^{-2} \mathrm{~s}^{-1}$ at $25 \pm 1^{\circ} \mathrm{C}$ and $60 \%$ $\mathrm{RH}$ for $45 \mathrm{~min}$ in a growth chamber. Measurements (three replicates per treatment and three readings per replicate, $n=9$ ) were carried out on leaves acclimatized for $10 \mathrm{~min}$ to the leaf chamber conditions. Measurements were recorded at $1,200 \mu \mathrm{mol}$ (photon) $\mathrm{m}^{-2} \mathrm{~s}^{-1}, 380 \mu \mathrm{mol}\left(\mathrm{CO}_{2}\right) \mathrm{mol}^{-1}$, $26 \pm 1{ }^{\circ} \mathrm{C}$ block temperature, and $60 \pm 5 \% \mathrm{RH}$. The $P_{\mathrm{N}}, C_{\mathrm{i}}$, $g_{\mathrm{s}}$ and $E$ were recorded. Water-use efficiency (WUE) was calculated as $P_{\mathrm{N}} / E$. Fluorescence parameters determined at light- and dark-adapted states, such as electron transport rate (ETR), maximum efficiency of PSII $\left(\mathrm{F} \sqrt{ } \mathrm{F}_{\mathrm{m}}\right)$, the efficiency of PSII $\left(\Phi_{\text {PSII }}\right)$, photochemical $\left(q_{\mathrm{P}}\right)$, and nonphotochemical (NPQ) quenching, were used. The ETR through PSII was calculated as $J_{\mathrm{T}}=\left[\left(\mathrm{F}_{\mathrm{m}}{ }^{\prime}-\mathrm{F}_{\mathrm{s}}\right) / \mathrm{F}_{\mathrm{m}}{ }^{\prime}\right] f I \alpha_{\text {leaf }}$, where $I$ is incident photon flux density [ $\mu$ mol(photon) $\left.\mathrm{m}^{-2} \mathrm{~s}^{-1}\right], \alpha_{\text {leaf }}$ is leaf absorbance typically assumed to be 0.85 and $f$ is the fraction of absorbed quanta used by PSII. The $f$ is typically assumed to be 0.5 based on the assumption of an equal distribution of photons between PSI and II (Miyake et al. 2005).

Multisignal Chl fluorescence was measured using multifunctional plant efficiency analyser (MPEA-2, Hansatech, UK). Measurements were recorded at room temperature on the adaxial surface of the fourth leaf from the top through continuous excitation with high-time resolution to investigate the rapid fluorescence induction (Oukarroum et al. 2015). The plants were dark-adapted for $45 \mathrm{~min}$ under ambient $\mathrm{CO}_{2}$ at $25 \pm 1^{\circ} \mathrm{C}$ using dark-adaptation facilities before the measurements of the Chl fluorescence. Leaves were illuminated with saturating red light of 3,000 $\mu \mathrm{mol}$ (photon) $\mathrm{m}^{-2} \mathrm{~s}^{-1}$ in order to close PSII reaction centers completely, and the fluorescence signals were recorded for $1.0 \mathrm{~s}$ on a $4-\mathrm{mm}$ diameter area of a dark-adapted intact leaf. The PF and DF detector used $730 \pm 15 \mathrm{~nm}$ wavelength of $3000 \mu \mathrm{mol}$ (photon) $\mathrm{m}^{-2} \mathrm{~s}^{-1}$ intensity. The instrument recorded $\mathrm{PF}$ and DF when the actinic light was on (light interval) and off (dark interval), respectively. The recorded data were downloaded into M-PEA Plus software (version 1.10) and comprehensive analysis was performed with its data analysis module.

Different kinetic parameters calculated of $\mathrm{Chl} a$ fluorescence recording were summarized as Table 1S (supplement). In PF curve, $\delta F_{I P}=\left(F_{P}-F_{I}\right)$ is the ratio of PSII:PSI, where $F_{P}$ is maximum fluorescence measured after approximately $200 \mathrm{~ms}$ of illumination and $F_{I}$ the fluorescence step that occurred after approximately $30 \mathrm{~ms}$, and it was calculated following Schansker et al. (2005). The $\delta \mathrm{V}_{\text {IP }}$ was calculated as $\left[\delta \mathrm{V}_{\mathrm{IP}}=\left(\mathrm{F}_{\mathrm{m}}-\mathrm{F}_{30 \mathrm{~ms}}\right) /\left(\mathrm{F}_{\mathrm{m}}-\mathrm{F}_{0}\right)\right]$, and indicated the electron transport around the PSI to reduce the final acceptors (i.e., ferredoxin and NADP) of the electron transport chain (Schansker et al. 2005). The DF induction curve was analyzed following Goltsev et al. (2009) and Oukarroum et al. (2013). Initial minimum 
value of DF was taken as $\mathrm{D}_{0}$. First maxima of the induction curve $\left(\mathrm{I}_{1}\right)$ represented the photochemical accumulation of light-emitting states of the PSII RC or delayed fluorescence precursors and nonphotochemical increase of the delayed fluorescence due to the electrical gradient formed by PSI when P700 is oxidized (Goltsev et al. 2009). The second maxima $\left(\mathrm{I}_{2}\right)$ in the range of I-P phase of PF curve represented prolonged reopening of PSII RCs by electron transfer from the reduced $\mathrm{Q}_{\mathrm{B}}$ to $\mathrm{PQ}$ before the reduction of the PQ pool. The final maxima $\left(\mathrm{I}_{4}\right)$ appeared during the slight decrease of the PF intensity and oxidation of P700. $\mathrm{I}_{4}$ represented the formation of the proton gradient (Evans and Crofts 1973, Goltsev et al. 2009) that increases the rate constant of radiative recombination in the PSII RCs. The minimum of the DF curve $\left(D_{2}\right)$ indicated of the reducing activity of the PSII complex. The ratio of $\mathrm{I}_{1} / \mathrm{I}_{2}$ and $\mathrm{I}_{4} / \mathrm{D}_{2}$ were calculated; this represented electron flow in PSII (Goltsev et al. 2012) and transmembrane proton gradient (Goltsev et al. 2005), respectively.

Estimating the carboxylation, rate of photosynthetic electron flow and photorespiration: Using $P_{\mathrm{N}}-C_{\mathrm{i}}$ curve, the maximum carboxylation rate $\left(V_{\mathrm{cmax}}\right)$ allowed by Rubisco, rate of photosynthetic electron transport supporting $\mathrm{NADP}^{+}$reduction for RuBP regeneration $\left(J_{\max }\right)$, triose phosphate utilization (TPU), dark respiration $\left(R_{\mathrm{D}}\right)$, and mesophyll conductance $\left(g_{\mathrm{m}}\right)$, at the measurement light intensity, were inferred by $P_{\mathrm{N}}-C_{\mathrm{i}}$ curve fitting facilities according to Sharkey et al. (2007) and Sharkey (2016). The electron flow through PSII to RuBP carboxylation $\left(J_{\mathrm{C}}\right)$ and oxygenation $\left(J_{0}\right)$ was allocated following Sharkey et al. (2007) and Sharkey (2016). $J_{0}$ was calculated as $2 / 3 \times\left[J_{\mathrm{T}}-4 \times\left(P_{\mathrm{N}}+R_{\mathrm{D}}\right)\right]$, and $J_{\mathrm{C}}$ as $1 / 3 \times\left[J_{\mathrm{T}}+8 \times\right.$ $\left.\left(P_{\mathrm{N}}+R_{\mathrm{D}}\right)\right]$, where $P_{\mathrm{N}}$ is $\mathrm{CO}_{2}$ assimilation and $R_{\mathrm{D}}$ represents the rate of mitochondrial respiration. $R_{\mathrm{D}}$ was taken from the linear region of the light-response curve between PPFDs of $0-100 \mu \mathrm{mol}$ (photon) $\mathrm{m}^{-2} \mathrm{~s}^{-1}$ and inferred following Sharkey et al. (2007). The Rubisco content was inferred using equation $\mathrm{y}=35.3 \mathrm{x}+6.6$ according to Yamori et al. (2010), where $\mathrm{x}$ is Rubisco content $\left(\mu \mathrm{mol} \mathrm{m} \mathrm{m}^{-2}\right)$, and $\mathrm{y}$ is $V_{\text {cmax }}\left[\mu \operatorname{mol}\left(\mathrm{CO}_{2}\right) \mathrm{m}^{-2} \mathrm{~s}^{-1}\right]$.

Sugar and starch contents: For extraction of soluble sugar contents, the preweighed fresh samples were extracted with $80 \%$ ethanol. The residual pellet left after extraction of sugar was digested with $52 \%$ perchloric acid for starch estimation. The soluble sugar and starch contents were estimated following anthrone-sulphuric acid method using $0.2 \%$ anthrone reagent in chilled and concentrated $\mathrm{H}_{2} \mathrm{SO}_{4}$. Glucose was used as standard and the absorbance was measured at $630 \mathrm{~nm}$. Obtained values were multiplied by a factor of 0.9 to convert the glucose value to starch. Sugar and starch contents were expressed as moles per fresh mass.

Histochemical detection of $\mathrm{H}_{2} \mathrm{O}_{2}, \mathrm{O}_{2}^{-}$and starch: Hydrogen peroxide and $\mathrm{O}_{2}{ }^{-}$radical accumulation were detected in vivo in leaves of stressed and unstressed tobacco. The samples were immersed in nitroblue tetrazolium (NBT) solution $\left(1 \mathrm{mg} \mathrm{ml}^{-1}\right.$ in $10 \mathrm{mM}$ phosphate buffer; $\mathrm{pH}$ 7.8) at room temperature for $2 \mathrm{~h}$, thereafter exposed to high irradiance for $12 \mathrm{~h}$ until blue spots showing accumulation of $\mathrm{O}_{2}^{-}$appeared. The presence of $\mathrm{H}_{2} \mathrm{O}_{2}$ was detected by immersing the leaf samples in 3,3-diaminobenzidine (DAB) solution $\left(1 \mathrm{mg} \mathrm{ml}^{-1}\right.$ in $10 \mathrm{mM}$ phosphate buffer; $\mathrm{pH}$ 3.8) at room temperature for $6 \mathrm{~h}$ in the dark, thereafter exposing to the light until brown spots showing accumulation of $\mathrm{H}_{2} \mathrm{O}_{2}$ appeared. Before documentation, the samples were washed with ethanol to bleach out the Chl. Samples showing dark color or stain were considered to contain more amount of $\mathrm{H}_{2} \mathrm{O}_{2}$ and $\mathrm{O}_{2}^{-}$.

Histochemical localization of starch was performed (Yang et al. 2014) in plants grown under different levels of stress. The leaf discs were immersed in boiling $\left(100^{\circ} \mathrm{C}\right)$ water for $1 \mathrm{~min}$. Subsequently, the samples were immersed in boiling ethanol (95\%) for $10 \mathrm{~min}$ for bleaching. The decolorized leaf discs were stained with iodine $\left(I_{2}\right)$ and potassium iodide (KI) solution $(1: 2)$ for $1 \mathrm{~min}$. The background color was removed by boiling the stained plants in ethanol (95\%) for $15 \mathrm{~s}$. The samples were washed with ethanol (95\%) at RT and visualized using Canon Eos $760 D$ camera.

Statistical analysis: The experiment was performed in triplicate with a minimum of three biological replicates. The data were subjected to one-way analysis of variance (ANOVA) for analysis of variance to determine the significance among mean values of control and treated plants. ANOVA was followed by Duncan's multiple range test (DMRT) for comparison of means. The data was presented as mean $\pm \mathrm{SE}$ and significant differences in mean values of control and stressed plants by the DMRT at $0.05 \%$ probability level were denoted by different lowercase letters.

\section{Results}

Salt and drought stress altered the plant physiology: The drought and salt stress caused a significant decrease in solute potential; it reached minimum (more negative value) in tobacco grown under $0.2 \mathrm{M} \mathrm{NaCl}$ stress (Fig. $1 \mathrm{~S} A$, supplement). The RWC in leaves decreased significantly under stress (Fig. 1SB, supplement) conditions. The stresses caused a decrease in contents of photosynthetic pigments; the decrease was higher in plants grown under $\mathrm{NaCl}$ stress than that of PEG stress (Fig. 1A,B).

The accumulation of total soluble sugars in tobacco leaves increased significantly under drought and salt stress (Fig. 1SC, supplement). The increase was the highest in tobacco grown under $10 \%$ PEG stress. Under $\mathrm{NaCl}$ stress, the increase in soluble sugars was comparatively lower than that in the plants under PEG stress. Beside accumulation of soluble sugar contents, the starch contents were found significantly lower in tobacco grown under stress as compared with control (Fig. 1SD, supplement). Further, the in vivo localization of starch showed a lower accumulation of starch in tobacco leaves under stress conditions (Fig. 2A). The in vivo localization of $\mathrm{H}_{2} \mathrm{O}_{2}$ through DAB staining and $\mathrm{O}_{2}^{-}$through NBT staining (Fig. $2 B, C)$ in leaf discs showed stress-caused accumulation of 


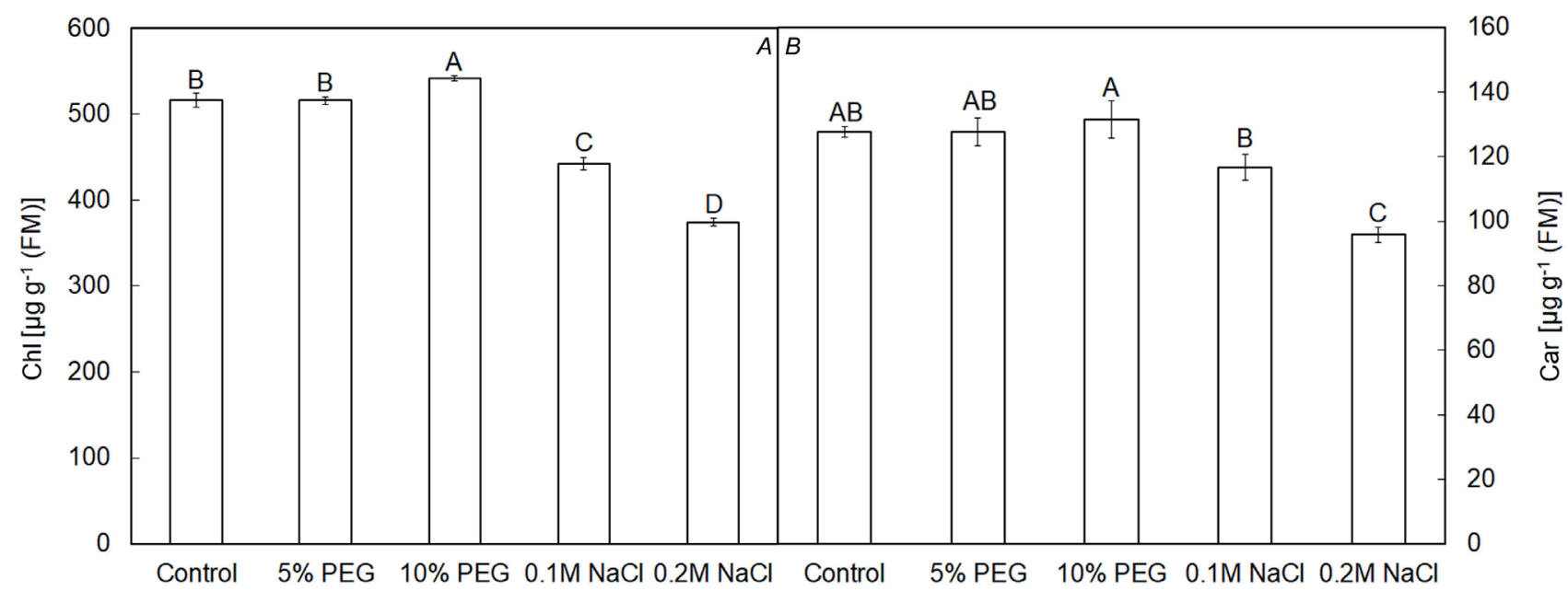

Fig. 1. Comparison of total chlorophyll $(A)$, and carotenoids $(B)$ contents in leaves of tobacco plants $(n=3)$ grown under control, $5 \%$ and $10 \%$ PEG, $0.1 \mathrm{M}$ and $0.2 \mathrm{M} \mathrm{NaCl}$ stress.

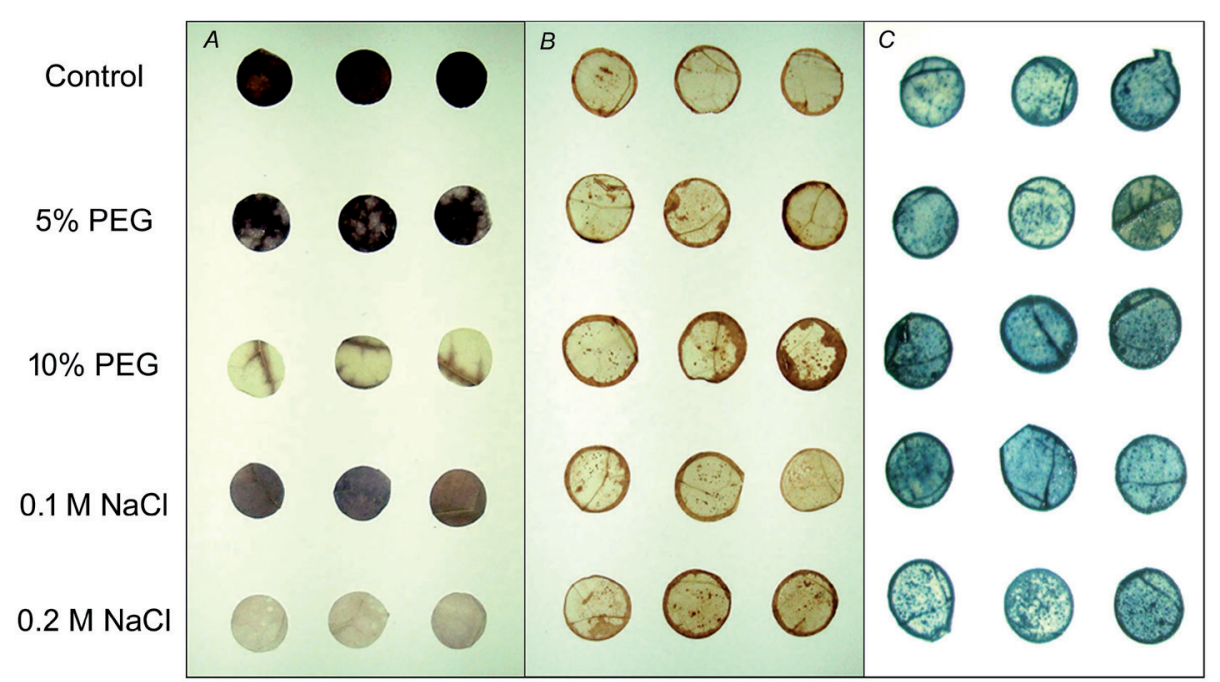

Fig. 2. In vivo localization and comparison of $(A)$ starch, $(B) \mathrm{H}_{2} \mathrm{O}_{2}$, and $(C) \mathrm{O}_{2}^{-}$in leaves of tabacco grown under control, $5 \%$ and $10 \%$ PEG, $0.1 \mathrm{M}$ and $0.2 \mathrm{M} \mathrm{NaCl}$ stress. reactive oxygen species (ROS) in leaves.

Stress reduced the gas exchange and photosynthetic performance: The $P_{\mathrm{N}}, g_{\mathrm{s}}, C_{\mathrm{i}}$, and $E$ decreased significantly under stress conditions (Fig. $3 A-D$ ). The decrease in photosynthetic measurements were found in accordance with the level of stress. The $P_{\mathrm{N}}$ and $g_{\mathrm{s}}$ were found strongly correlated $(r=0.94)$. Similarly, $g_{\mathrm{s}}$ had a direct influence on $C_{\mathrm{i}}(r=0.86)$ and $E(r=0.98)$. The WUE varied accordingly and was estimated higher under stress conditions (Fig. $3 E$ ) because of stomatal closure and reduced transpiration.

The $F_{v} / F_{m}$ was significantly lower in the plants under stress conditions as compared with control conditions. $\Phi_{\text {PSII }}$ was significantly lower in tobacco under stress conditions. Similarly, ETR was estimated significantly lower in tobacco under stress conditions as compared with control conditions. The $P_{\mathrm{N}}$ showed a positive correlation with $\Phi_{\mathrm{PSII}}$ $(r=0.97)$ and ETR $(r=0.97)$. The NPQ increased under stress conditions. The $\mathrm{q}_{\mathrm{P}}$ decreased significantly under stress conditions (Fig. 4A-E). The fluorescence parameters $\left(\mathrm{F}_{\mathrm{v}} / \mathrm{F}_{\mathrm{m}}, \Phi_{\mathrm{PSII}}, \mathrm{ETR}, \mathrm{NPQ}\right.$, and $\left.\mathrm{q}_{\mathrm{P}}\right)$ showed a direct relation with $P_{\mathrm{N}}$.
Stress influenced carboxylation, oxygenation, TPU, and electron flow through PSII and photorespiration: With an increase in PPFD, $P_{\mathrm{N}}$ increased in control and stress treatments, however, it was higher in control at given PPFD under stress conditions (Fig. 5A). Similarly, with an increase in $\mathrm{CO}_{2}$ concentration and $C_{\mathrm{i}}, P_{\mathrm{N}}$ increased in control and stress treatments. The $P_{\mathrm{N}}$ was higher in control at given $C i$ under stress conditions (Fig. $5 B$ ). The $V_{\text {cmax }}$ decreased in tobacco under stress, and the decrease was more prominent under PEG stress as compared to $\mathrm{NaCl}$ stress. The $J_{\max }$ was estimated in accordance with $V_{\text {cmax }}$ (Fig. 6A,B). The TPU decreased under stress conditions; this was more prominent under PEG stress. The $R_{\mathrm{D}}$ increased in tobacco leaves under stress conditions, and it was estimated the highest under $\mathrm{NaCl}$ stress. The $g_{\mathrm{m}}$ and Rubisco contents were lower under stress conditions (Fig. $6 B$ ). The $J_{\mathrm{C}}$ increased with light intensity and $J_{0}$ decreased with $C_{\mathrm{i}}$ under control, drought, and salinity stress conditions (Fig. 2S, supplement). 


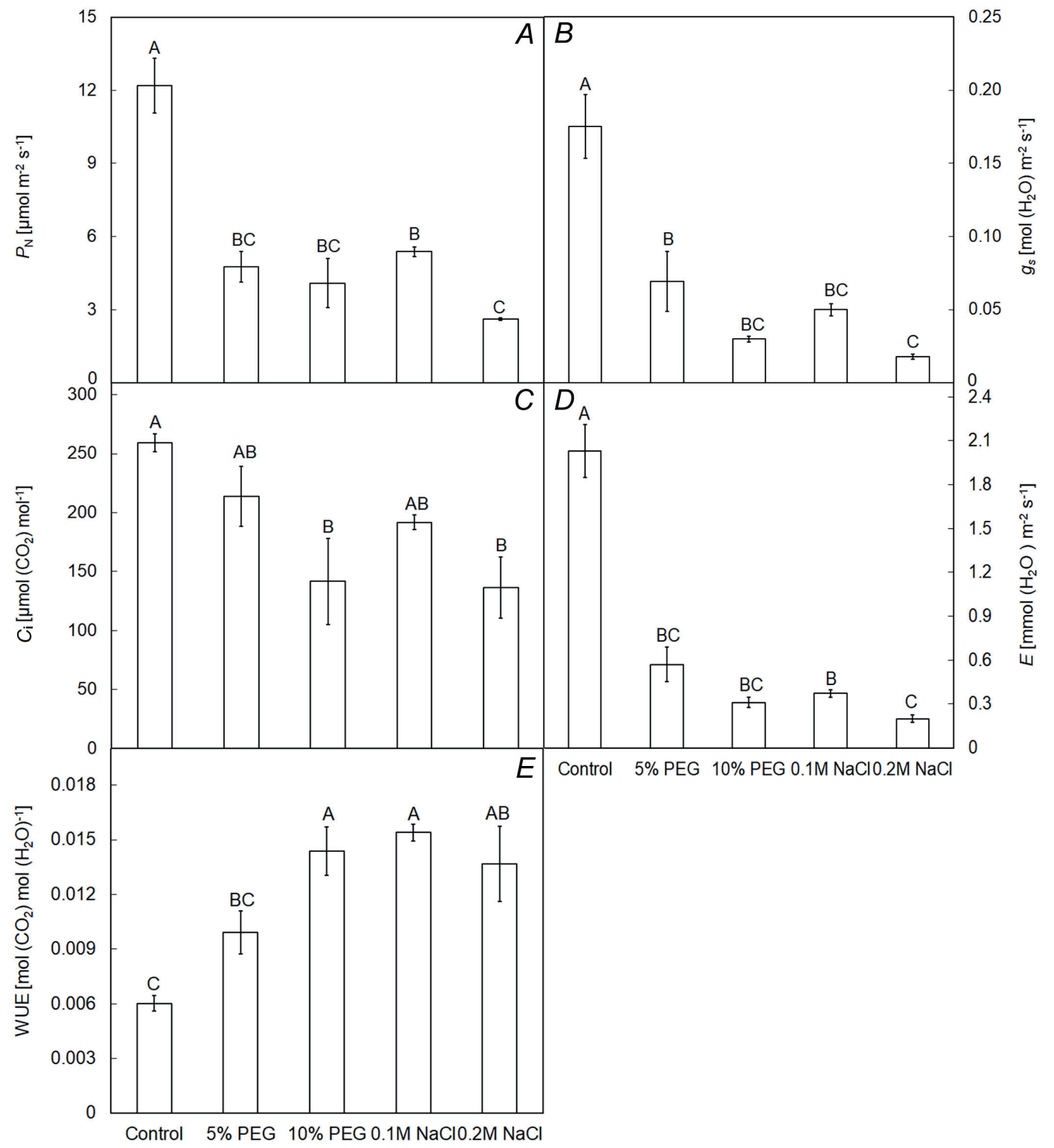

Fig. 3. Comparison of net $\mathrm{CO}_{2}$ assimilation rate $\left(P_{\mathrm{N}}, A\right)$, stomatal conductance $\left(g_{\mathrm{s}}, B\right)$, intercellular $\mathrm{CO}_{2}$ concentration $\left(C_{\mathrm{i}}, C\right)$, transpiration $(E, D)$, and water-use efficiency $(E)$ in leaves of tobacco $(n=9)$ grown under control, $5 \%$ and $10 \%$ PEG, $0.1 \mathrm{M}$ and $0.2 \mathrm{M} \mathrm{NaCl}$ stress.

Multisignal fluorescence: From PF and DF measurements, various $\mathrm{Chl}$ fluorescence kinetic parameters were determined (Table 1S, supplement). The $\mathrm{T}_{\mathrm{Fm}}$ is time to achieve $\mathrm{F}_{\mathrm{m}}$ and it decreased in leaves of tobacco under stress conditions, however, it was significantly higher under $10 \%$ PEG stress. The area represents pool size of electron acceptors $\left(\mathrm{Q}_{\mathrm{A}}\right)$ on reducing side of PSII and it was reduced significantly under stress conditions and was the lowest in leaves of tobacco under $10 \%$ PEG treatment. The emission by excited Chl $a$ molecule in the PSII antenna $\left(\mathrm{F}_{0}\right)$ was higher under stress conditions and was found the highest in leaves of tobacco under $10 \%$ PEG stress. The maximum fluorescence $\left(\mathrm{F}_{\mathrm{m}}\right)$ and the maximum capacity for photochemical quenching $\left(\mathrm{F}_{\mathrm{v}}\right)$ were recorded lower in PEG treatments, while, after $\mathrm{NaCl}$ treatments, no statistically significant difference from the control was found. $\mathrm{F}_{0} / \mathrm{F}_{\mathrm{m}}$ increased under stress conditions, and it was significantly higher in leaves of tobacco under PEG stress. The maximum quantum efficiency of PSII $\left(\mathrm{F}_{\mathrm{v}} / \mathrm{F}_{\mathrm{m}}\right)$ was lower under stress conditions. The $\mathrm{F}_{\mathrm{V}} / \mathrm{F}_{0}$ was estimated lower under stress conditions. The $\mathrm{V}_{\mathrm{J}}$ and $\mathrm{V}_{\mathrm{I}}$ were estimated higher (Fig. 7A) under stress conditions. Both absorption $(\mathrm{ABS} / \mathrm{RC})$ and dissipation per reaction centre $\left(\mathrm{DI}_{0} / \mathrm{RC}\right)$ were recorded higher under stress conditions. $\mathrm{TR}_{0} / \mathrm{RC}$ in leaves of tobacco increased under stress conditions and the increase was higher under PEG stress. The $\mathrm{ET}_{0} / \mathrm{RC}$ and 


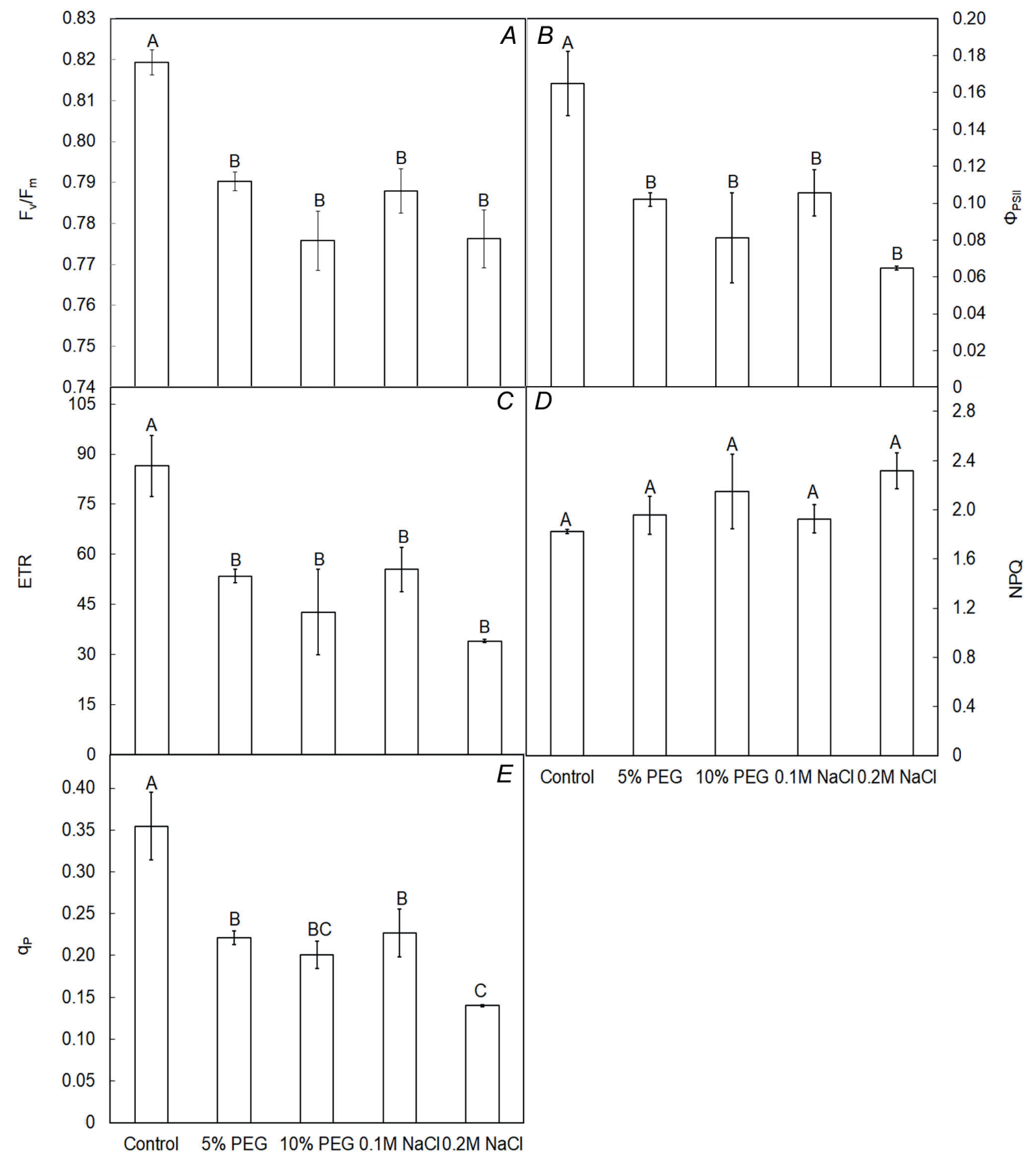

Fig. 4. Comparison of maximum quantum efficiency of PSII photochemistry $\left(\mathrm{F}_{\mathrm{v}} / \mathrm{F}_{\mathrm{m}}, A\right)$, efficiency of PSII $\left(\phi_{\text {PSII }}, B\right)$, electron transport rate $(\mathrm{ETR}, C)$, nonphotochemical quenching $(\mathrm{NPQ}, D)$, and photochemical quenching $\left(\mathrm{q}_{\mathrm{p}}, E\right)$ in leaves of tobacco $(n=9)$ grown under control, $5 \%$ and $10 \%$ PEG, $0.1 \mathrm{M}$ and $0.2 \mathrm{M} \mathrm{NaCl}$ stress.

$\mathrm{RE}_{0} / \mathrm{RC}$ were reduced significantly under stress conditions. $\mathrm{ABS} / \mathrm{CS}_{0}, \mathrm{DI}_{0} / \mathrm{CS}_{0}$, and $\mathrm{TR}_{0} / \mathrm{CS}_{0}$ increased in leaves of tobacco under PEG and the increase was insignificant under $\mathrm{NaCl}$ stress. The $\mathrm{ABS} / \mathrm{CS}_{0}$ is PSII activity in terms of cross-section, and it is in accordance with $\mathrm{ABS} / \mathrm{RC}$. $\mathrm{ET}_{0} / \mathrm{CS}_{0}$ and $\mathrm{RE}_{0} / \mathrm{CS}_{0}$ decreased with increasing stress (Fig. 7B). The $\gamma(\mathrm{RC}) /\left[(1-\gamma(\mathrm{RC})], \Phi\left(\mathrm{P}_{0}\right) /\left[\left(1-\Phi\left(\mathrm{P}_{0}\right)\right]\right.\right.$ and $\psi\left(\mathrm{E}_{0}\right) /\left[1-\psi\left(\mathrm{E}_{0}\right)\right]$ reflect portion of absorbed energy reaching $\mathrm{RC}$, activity of the water-splitting complex, and light-independent thermal reaction, respectively, and these declined under stress conditions. The $\left[\delta R_{0} /\left(1-\delta R_{0}\right)\right]$ indicate primary photochemistry and was estimated higher under mild stress and was reduced significantly with increased stress. The $\mathrm{PI}_{\text {Total }}$ was found lower under stress treatments. The driving force based on absorption basis $\left(\mathrm{DF}_{\mathrm{abs}}\right)$ and energy conservation from absorbed photons by PSII to reduction of PSI end acceptors ( $\left.\mathrm{DF}_{\text {Total }}\right)$ and nonphotochemical de-excitation rate constant $(\mathrm{kP} /$ $\mathrm{ABS} \times \mathrm{kF}$ ) were lower under stress treatments (Fig. 7C). The accumulation of closed RCs $\left(\delta \mathrm{Vg} / \mathrm{dt}_{0}\right)$ and the excitation energy transfer between the RCs $\left(\delta \mathrm{V} / \mathrm{dt}_{0}\right)$ were significantly higher in tobacco under stress conditions. The 


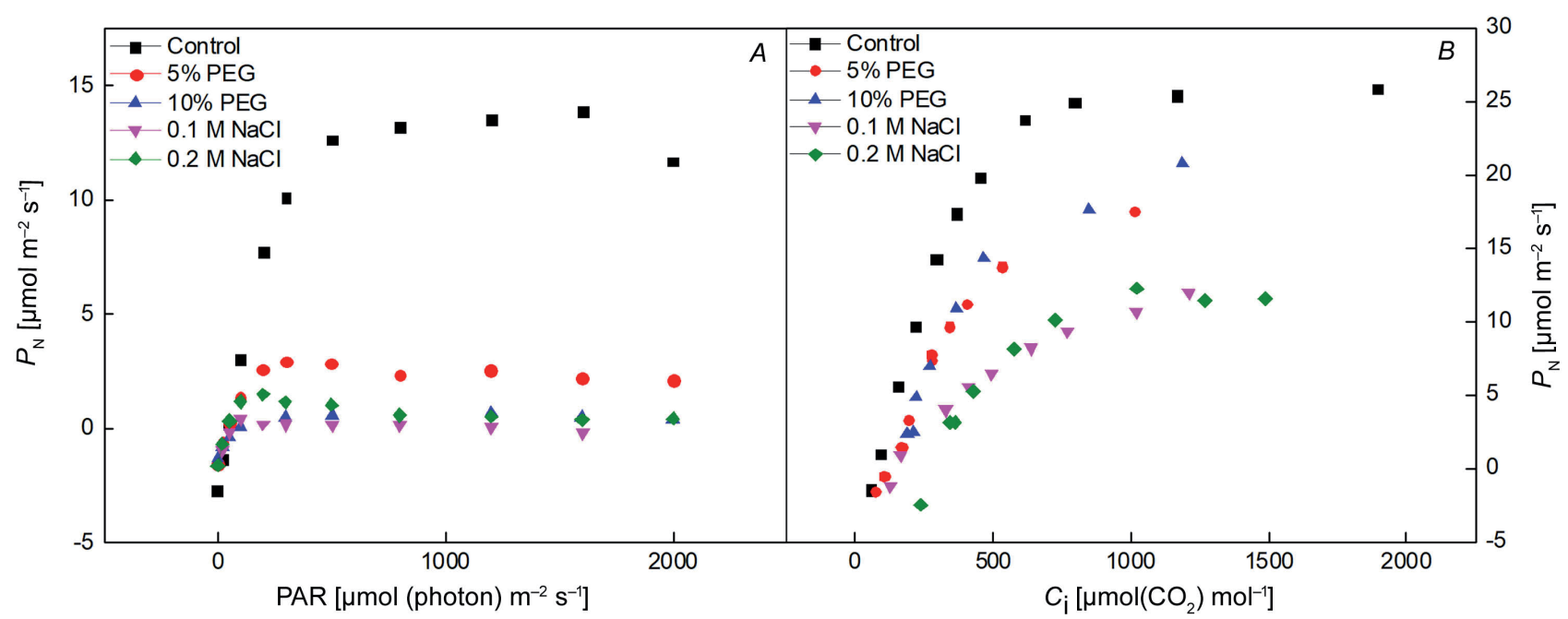

Fig. 5. Light- $(A)$ and $\mathrm{CO}_{2}$-response curve $\left(P_{\mathrm{N}}-\mathrm{C}_{i}, B\right)$ in leaves of tobacco $(n=3)$ under control, $5 \%$ and $10 \%$ PEG, $0.1 \mathrm{M}$ and $0.2 \mathrm{M} \mathrm{NaCl}$ stress.

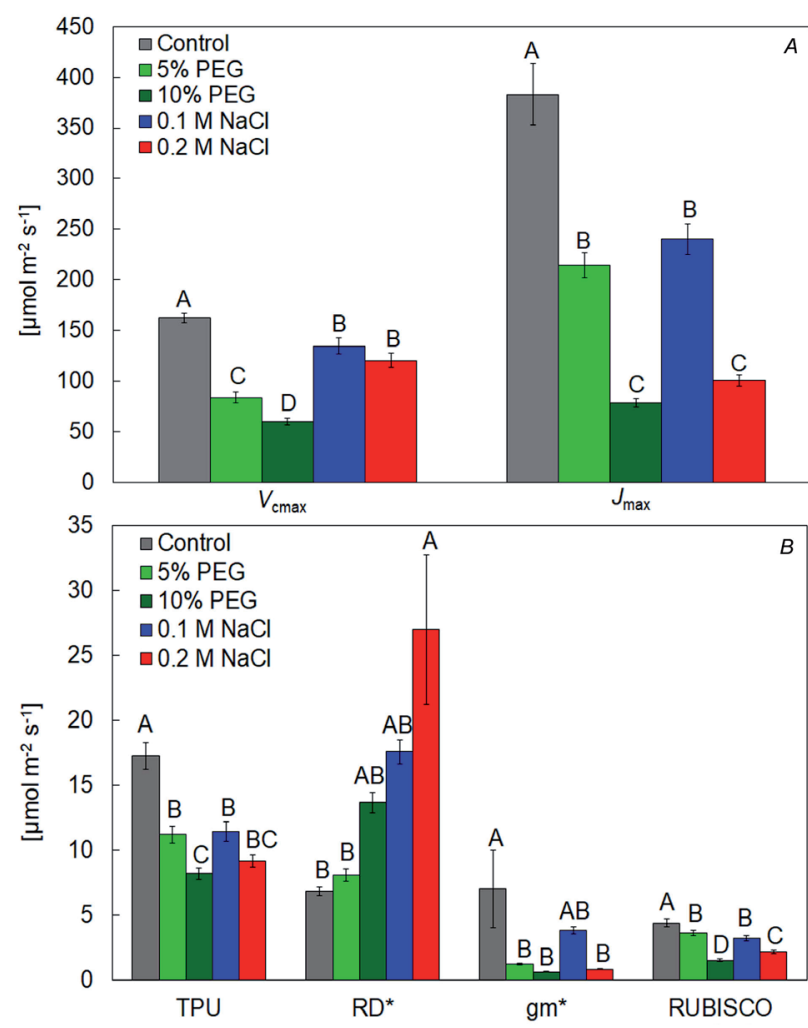

Fig. 6. Comparison of maximum carboxylation rate $\left(V_{\mathrm{cmax}}\right)$, maximum electron transport rate/electron transport capacity $\left(J_{\max }\right)$, triose phosphate utilization (TPU), dark respiration $\left(R_{\mathrm{D}}\right)$, mesophyll conductance $\left(g_{\mathrm{m}}\right)$, and Rubisco contents in leaves of tobacco plants $(n=3)$ grown under control, $5 \%$ and $10 \%$ PEG, $0.1 \mathrm{M}$ and $0.2 \mathrm{M} \mathrm{NaCl}$ stress.

average redox state of $\mathrm{Q}_{\mathrm{A}}\left(\mathrm{S}_{\mathrm{M}} / \mathrm{T}_{\mathrm{Fm}}\right)$ and maximum quantum yield of primary PSII photochemistry $\left[\Phi\left(\mathrm{P}_{0}\right)\right]$ were lower in tobacco under stress conditions. The efficiency of electron movement $\left[\psi\left(\mathrm{E}_{0}\right)\right]$ and quantum yield for electron transport $\left[\Phi\left(\mathrm{E}_{0}\right)\right]$ were significantly lower in stress treatments. The $\delta\left(R_{0}\right)$ (efficiency for an electron from the intersystem electron carriers to end electron acceptors at the PSI acceptor side) improved slightly under 5\% PEG and $0.1 \mathrm{M} \mathrm{NaCl}$, while decreased under higher stress. The $\Phi\left(R_{0}\right)$ (quantum yield for reduction of end electron acceptors at the PSI acceptor side) was reduced under stress conditions (Fig. 7D).

The kinetics of induction curve of PF and DF were plotted on a logarithmic time scale (Fig. 8A,B). The PF curve showed $\mathrm{O}, \mathrm{J}, \mathrm{I}$, and $\mathrm{P}$ phases. The DF showed a fast rise, polyphasic decline, and long-lasting plateau phase. The DF fast rises phase corresponded the rate of PF increase from $\mathrm{J}-\mathrm{I}$ step and the polyphasic with I-P phase of the PF curve. The DF decreased under stress conditions and the values of $\delta F_{I P}$ and $\delta V_{\text {IP }}$ were reduced under stress conditions (Table $2 \mathrm{~S}$, supplement). The $\mathrm{I}_{1} / \mathrm{I}_{2}$ decreased in tobacco grown under 5\% PEG and $0.1 \mathrm{M} \mathrm{NaCl}$ stress, thereafter increased. Similarly, the $\mathrm{I}_{4} / \mathrm{D}_{2}$ was reduced under stress conditions (Table 2S).

The ETR, estimated through modulated fluorescence measurement, was lower under stress conditions. Similarly in multisignal fluorescence measurements, the electron fluxes, such as $\mathrm{ET}_{0} / \mathrm{RC}, \mathrm{RE}_{0} / \mathrm{RC}, \mathrm{ET}_{0} / \mathrm{CS}_{0}$, and $\mathrm{RE}_{0} / \mathrm{CS}_{0}$, were lower in leaves of tobacco under stress conditions. The maximum quantum yields of primary PSII photochemistry $\left[\Phi_{\text {PSII }}\right.$ and $\left.\Phi\left(\mathrm{P}_{0}\right)\right]$ were found lower under stress conditions through both modulated and multisignal fluorescence. The $\Phi_{\mathrm{PSII}}$ and $\mathrm{CO}_{2}$ fixation (modulated fluorescence measurements) in tobacco leaves under stress conditions can be directly predicted by studying $\mathrm{PI}_{\mathrm{abs}}$ and $\mathrm{PI}_{\text {Total }}$ (multisignal fluorescence measurements).

\section{Discussion}

The drought and salt stresses negatively affected the growth and development of tobacco plants and caused the significant decrease in solute potential, RWC, and photosynthetic pigments. The decrease in solute potential of sap, RWC in leaves and photosynthetic pigments have been reported under drought and salinity stress in 


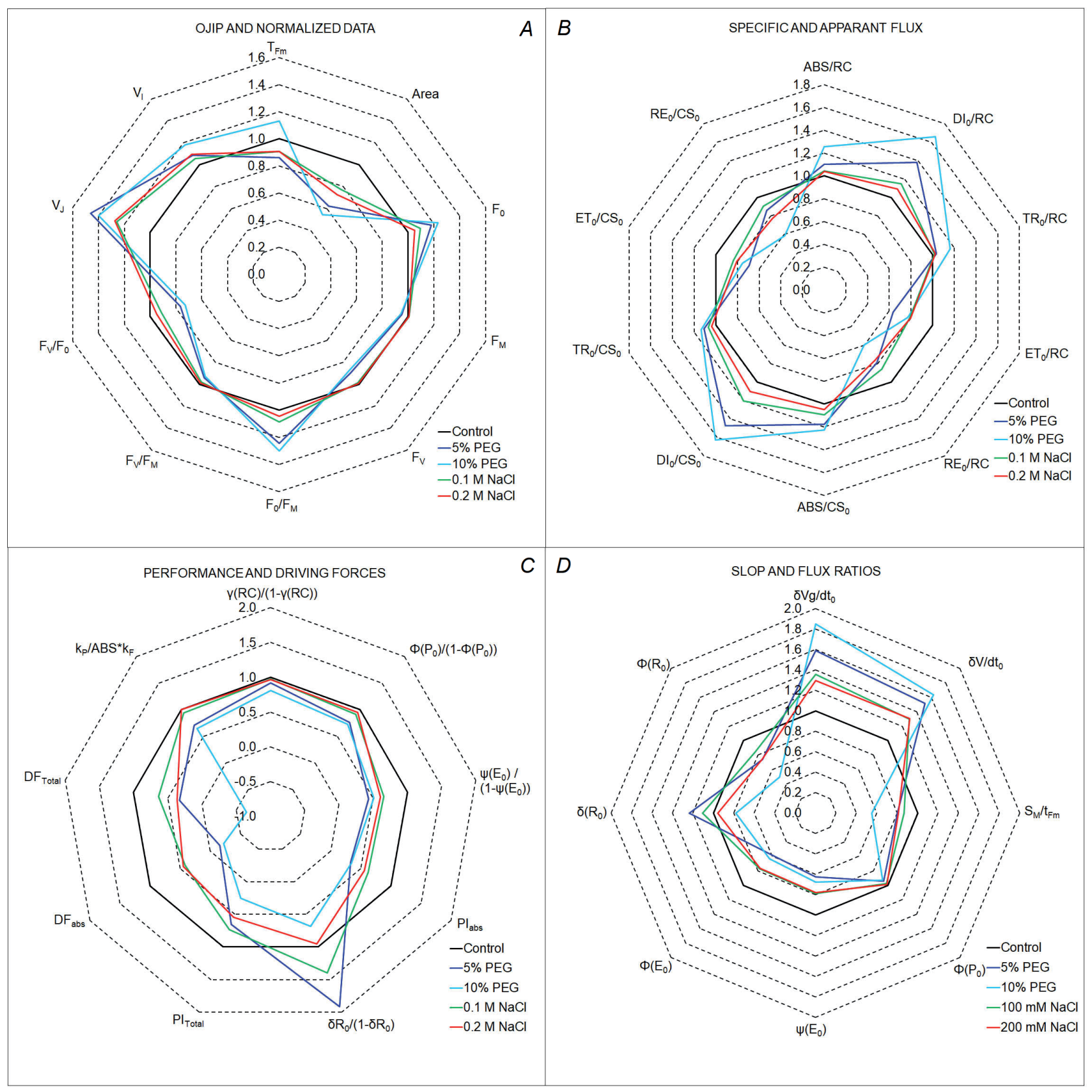

Fig. 7. Comparison of prompt and delayed fluorescence: The JIP and normalized data $(A)$, specific and apparent fluxes $(B)$, performance and driving forces $(C)$ and slops and flux ratios $(D)$ in leaves of tobacco plants $(n=9)$ under control, $5 \%$ and $10 \%$ PEG, $0.1 \mathrm{M}$ and $0.2 \mathrm{M} \mathrm{NaCl}$ stress.

both glycophytes and halophytes (Haque et al. 2017). Maintenance of intracellular ion homeostasis is fundamental to physiology of plants. Lower solute potential under stress indicated plant's adaptation toward drought and salinity stress. Similar results were observed in different reports during functional validation of transgenes under drought and salt stress (Kumari et al. 2017). Under salinity stress, lower pigment contents have been attributed to reduced biosynthesis of Chl in sunflower leaves (Santos 2004). The reduction in photosynthetic pigments is important, and this has a direct relationship to stress tolerance (Ahmad et al. 2005) as the pigments represent plant's efficiency to harvest or dissipate the excess light energy in PSI and PSII. Stress-induced inhibition of pigment synthesis and plant's adaptive strategy to avoid photoinhibition by decreasing light capture (Choinski et al. 2003) might be reasons for lower contents of pigment. Under PEG stress, immediate withdrawal of water from leaves might have diluted the effect of stress and maintained the pigment concentration under short-term exposure. 

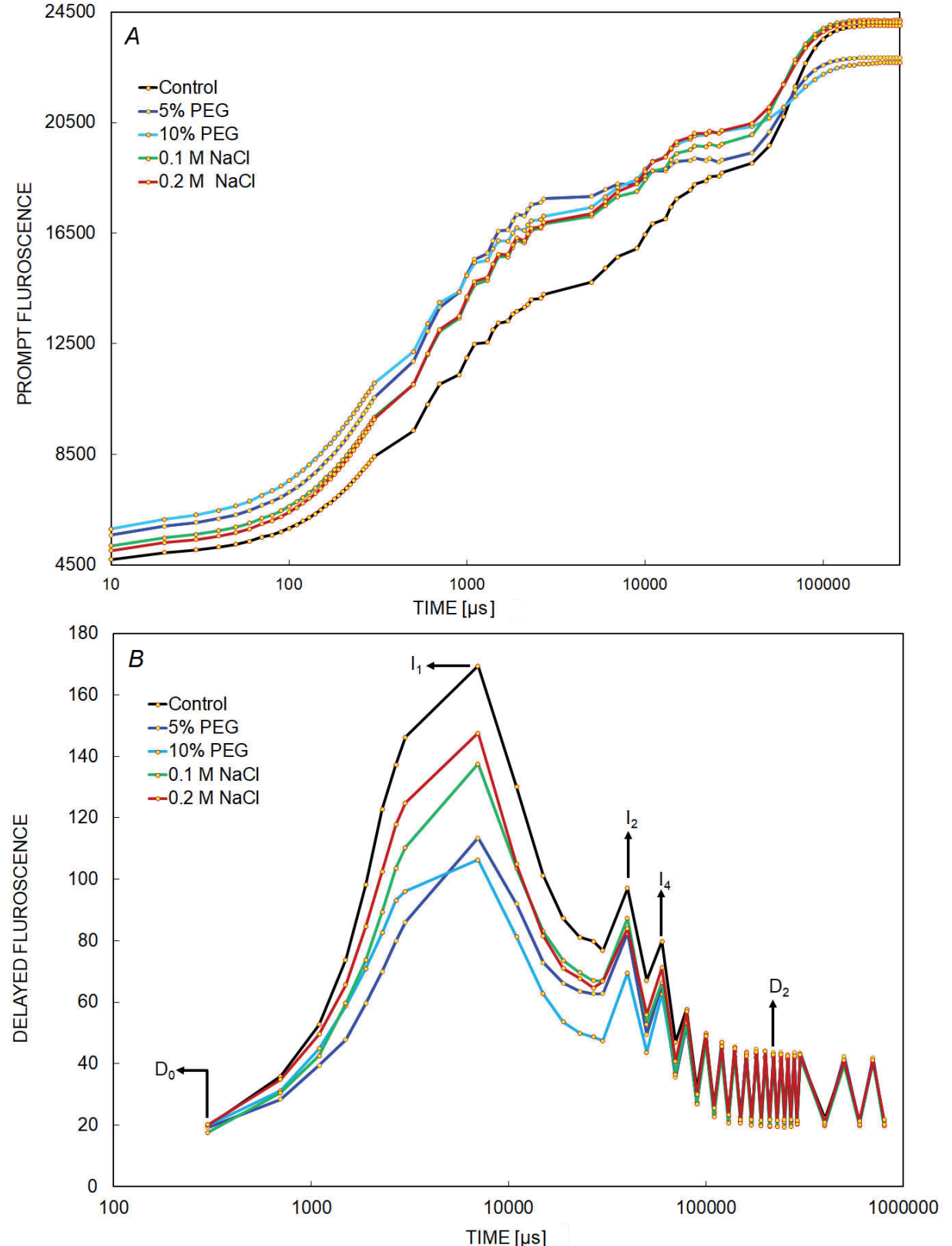

Fig. 8. The prompt $(A)$ and delayed $(B)$ fluorescence curves in leaves of tobacco plant grown under control and stress (drought and salt) conditions. The black, blue, pink, green, and red color represent the recording in the leaves of tobaccos $(n=9)$ under control, $5 \%$ and $10 \%$ PEG, $0.1 \mathrm{M}$ and $0.2 \mathrm{M} \mathrm{NaCl}$ stress, respectively.
The accumulation of sugar, starch, and ROS varied under drought and salinity stress. Sucrose and starch synthesis have been reported to be tightly coupled with the rate of $\mathrm{CO}_{2}$ assimilation (Foyer et al. 2000). A lower content of starch under stress conditions indicated accumulation of synthesized sugars as osmolytes and reduced conversion of synthesized sugar into starch. These results are in agreement with previous studies on different plant systems under stress conditions (Yang et al. 2014, Haque et al. 2017, Kumari et al. 2017). The in vivo localization of $\mathrm{H}_{2} \mathrm{O}_{2}$ and $\mathrm{O}_{2}{ }^{-}$clearly showed higher accumulation of ROS (Kumari et al. 2017), which might damage the metabolic machinery and thus affect photosynthesis negatively.

$P_{\mathrm{N}}$ is restricted by stomatal closure which limits diffusion of $\mathrm{CO}_{2}$ and causes a decrease in $C_{\mathrm{i}}$ under stress conditions and ultimately results in a reduction of Rubisco activity (Maroco et al. 2002). In present study, the stressinduced changes in $\mathrm{CO}_{2}$ assimilation could be accounted for changes in stomatal response. Under stress conditions, the stomatal limitation could be a reason for reduction in $\mathrm{CO}_{2}$ assimilation and similar results were reported in previous studies (Flexas et al. 2004, Debez et al. 2008). The lower water content leads to stomatal closure; in our case, the lower RWC in tobacco leaves under stress conditions clearly indicated the stomatal closure. The higher WUE indicated the conservation of water under stress conditions probably due to the accumulation of organic solutes. Thus, the present results clearly indicated that stress caused alterations in $g_{\mathrm{s}}$ that was the primary factor controlling the $P_{\mathrm{N}}, C_{\mathrm{i}}, E$, and WUE. The lower $g_{\mathrm{s}}$ and $E$ could be considered as an adaptive mechanism of plants as it helps reduce salt loading into leaves and maintain the 
salt below a toxic concentration (Moradi and Ismail 2007). With lower $\mathrm{CO}_{2}$ assimilation, the reduced activity of the Calvin-Benson $\left(\mathrm{C}_{3}\right)$ cycle under stress conditions could lead to an increased production of superoxide radicals on the acceptor side of PSI (Oukarroum et al. 2009).

The lower value of $F_{v} / F_{m}$ showed the adverse effect of stress on light-utilization efficiency of tobacco plants under stress. The positive correlation of $P_{\mathrm{N}}$ with $\Phi_{\mathrm{PSII}}$ and ETR showed a linear relationship among these parameters (Maxwell and Johnson 2000). The higher NPQ indicated dissipation of excess energy under stress conditions (Redondo-Gómez et al. 2006). The increase in NPQ is considered as a protective mechanism of the photosynthetic apparatus (Lawlor 2002). The decreased $\mathrm{q}_{\mathrm{P}}$ under stress conditions (Netondo et al. 2004) indicated the lesser availability of energy for the photochemical purpose under stress conditions. The present results suggested that decreased rate of photosynthesis might occur due to direct effect of stress on stomatal conductance (DionisioSese and Tobita 2000) and indirect effect of stress on photochemical functioning of plants (Moradi and Ismail 2007). The drought and salinity stress-induced limitation in $P_{\mathrm{N}}$ could lead to imbalance between PSII activity and electron requirements. This might result in over-excitation and photoinhibition thereof (Pérez-López et al. 2012).

The $g_{\mathrm{m}}$ was significantly lower in tobacco under stress conditions as compared to control (Flexas et al. 2004). Under stress conditions, decreased biosynthesis of Rubisco has been reported. Further, Rubisco activity in tobacco decreased due to accumulation of inhibitory molecules during stress. The $J_{\mathrm{C}}$ and $J_{0}$ indicated the electron flow devoted to the RuBP carboxylation and oxygenation, respectively (Fig. 2S). Differential activity of Rubisco has been reported in plants under stress conditions (Ashraf and Harris 2013). A significant reduction in Rubisco carboxylation activity, RuBP regeneration, and TPU utilization has been reported under stress conditions (Wilson et al. 2000, Maroco et al. 2002, Pérez-López et al. 2012). The decreased $g_{\mathrm{s}}$ caused decrease in $g_{\mathrm{m}}$ as the changes in $g_{m}$ can be as rapid as changes in $g_{s}$ (Centritto et al. 2003, Loreto et al. 2003). The stress affects diffusion of $\mathrm{CO}_{2}$ in the leaves through a decreased $g_{\mathrm{s}}$ and $g_{\mathrm{m}}$. This resulted in decreased $\mathrm{CO}_{2}$ concertation in chloroplasts as compare to intercellular $\mathrm{CO}_{2}$ concentration. The lower $P_{\mathrm{N}}$ in leaves of stress-affected tobacco was primarily due to decreased $g_{s}$ and $g_{m}$. Further, the stress-induced degradation of large subunit of Rubisco (Lee et al. 2016) along with decreased $g_{\mathrm{s}}$ and $g_{\mathrm{m}}$ cause a reduction in biochemical capacity to assimilate $\mathrm{CO}_{2}$ in tobacco leaves.

In multisignal fluorescence measurement, decreased $\mathrm{T}_{\mathrm{Fm}}$ indicated stress conditions. Under 10\% PEG stress, the relative increase in total $\mathrm{Chl}$ contents due to sudden withdrawal of water from leaf might be reason for increased $T_{F m}$. The area represents pool size of electron acceptors $\left(\mathrm{Q}_{\mathrm{A}}\right)$ on reducing side of PSII and the reduced area clearly indicated the blockage of electron transfer from reaction centers to quinone pool or at the donor side of PSII (Mehta et al. 2010). The increased $\mathrm{F}_{0}$ in plants under stress conditions may be considered as an indicator of damage to PSII (Bussotti et al. 2011) and this indicates heat dissipation in an uncontrolled manner, producing an excess of excitation power within the leaf. The decrease in $\mathrm{F}_{\mathrm{m}}$ may occur due to inhibition of electron transport at the donor side of the PSII causing accumulation of $\mathrm{P}_{680}{ }^{+}$ (Govindjee 1995) and decrease in the pool size of $Q_{A}$. The decreased $F_{m}$ has been reported to be associated with an increase in nonphotochemical quenching. The increased $\mathrm{F}_{0} / \mathrm{F}_{\mathrm{m}}$ under stress conditions (Ranjbarfordoei et al. 2006) indicated nonphotochemical quenching. The $\mathrm{F}_{\mathrm{v}} / \mathrm{F}_{\mathrm{m}}$ was reported lower under stress conditions (Netondo et al. 2004, Ranjbarfordoei et al. 2006, Salvatori et al. 2014) and this indicated reduction of the capacity of photosynthetic machinery for photochemical quenching of energy in PSII. The lower estimates of activity of water-splitting complex or oxygen evolving complex on the donor side of the PSII $\left(\mathrm{F}_{\mathrm{v}} / \mathrm{F}_{0}\right)$ under stress conditions (Ranjbarfordoei et al. 2006) is attributed to impairment in photosynthetic electron transport (Pereira et al. 2000). Similar to present study, Salvatori et al. (2014) observed higher $V_{J}$ and $V_{I}$ under stress conditions. The increased $\mathrm{V}_{\mathrm{J}}$ under stress conditions revealed a loss of $\mathrm{Q}_{\mathrm{A}}$ reoxidation capacity and inhibition of electron transport at the acceptor side of PSII. In canola, decrease in $\mathrm{V}_{\mathrm{J}}$ was recorded during salt stress (Jafarinia and Shariati 2012). The higher absorption and dissipation under stress conditions were found in consonance with Kalaji et al. (2011), Mathur et al. (2013), and Demetriou et al. (2007). The higher $\mathrm{F}_{0}$ indicated the increased antenna size with active and inactive reaction centers; the addition of inactive centers to antenna size might be cause for increased ABC/RC. Further Mathur et al. (2013) reported higher ABS/RC due to conversion of PSII units into heat sinks units along with inactive RCs. The inactive centers could not trap photons, leading to an increase in the amount of untrapped photons and thus to the increase of $\mathrm{DI}_{0} / \mathrm{RC}$ (Mathur et al. 2013).

The increased $\mathrm{TR}_{0} / \mathrm{RC}$ indicates inefficiency of reoxidation of reduced $\mathrm{Q}_{\mathrm{A}^{-}}$or electron transfer to $\mathrm{Q}_{\mathrm{B}}$ and this leads to a loss of energy as dissipation (Mathur et al. 2013). The $\mathrm{ET}_{0} / \mathrm{RC}$ is maximum electron transport flux per PSII reaction center; it reflects the activity of the active reaction centers (Misra et al. 2001). In the present case, the reduced $\mathrm{ET}_{0} / \mathrm{RC}$ indicates reduced rate of reopening of $\mathrm{RCs}$ through reoxidation of $\mathrm{Q}_{\mathrm{A}^{-}}$. Under saline conditions, both increase and decrease in $\mathrm{ET}_{0} / \mathrm{RC}$ has been reported (Mathur et al. 2013, Demetriou et al. 2007). The Chl contents also influence $\mathrm{ABS} / \mathrm{RC}$ and $\mathrm{ABS} / \mathrm{CS}_{0}$ (Misra et al. 2001). Stress-caused inactivation of reaction center may be the reason for lower $\mathrm{ET}_{0} / \mathrm{CS}_{0}$ (Mehta et al. 2010). Variations in $\mathrm{ABC} / \mathrm{CS}_{0}$ and $\mathrm{DI}_{0} / \mathrm{RC}$ under stress conditions indicate changes in the architecture of light-harvesting complex (Fusaro et al. 2016). The reduced $\gamma(\mathrm{RC}) /$ $[(1-\gamma(\mathrm{RC})]$ under stress conditions indicated low density of PSII reaction centers in PSII Chl antenna bed (Krüger et al. 2014). Further lower estimates of $\Phi\left(\mathrm{P}_{0}\right) /\left[\left(1-\Phi\left(\mathrm{P}_{0}\right)\right]\right.$ and $\psi\left(\mathrm{E}_{0}\right) /\left[1-\psi\left(\mathrm{E}_{0}\right)\right]$ indicated reduced contribution of light reactions for primary photochemistry and of the dark reactions from $\mathrm{Q}_{\mathrm{A}}^{-}$to $\mathrm{PC}$, respectively. The $\left[\delta \mathrm{R}_{0} /\left(1-\delta \mathrm{R}_{0}\right)\right]$ estimates indicated higher contribution of PSI reducing its end acceptors under mild stress, which was reduced significantly under $10 \%$ PEG and $0.2 \mathrm{M} \mathrm{NaCl}$ 
stress. Similar to present study, the performance index was reported lower under stress treatments (Oukarroum et al. 2015, Dąbrowski et al. 2016, Kan et al. 2017). The lower estimates of $\Phi\left(\mathrm{P}_{0}\right)$ indicated the reduced efficiency of PSII. The lower estimates of $\Phi\left(\mathrm{R}_{0}\right)$ showed reduced quantum yield for reduction of the end electron acceptors at the PSI acceptor side.

In the present study, plateau and decline in PF and DF appeared almost at the same time (Strasser et al. 2010). The I-P phase depends on electrons originating in PSII flowing through PSI and the transient block on the acceptor side of PSI (Schansker et al. 2005). The lower increase in I-P phase under stress conditions indicated reduced activity of PSI. The $\delta \mathrm{F}_{\text {IP }}$ and $\delta \mathrm{V}_{\text {IP }}$ are amplitudes of fluorescence and indicate the relative contribution of the I-to-P rise to the OJIP-rise (Oukarroum et al. 2015, Salvatori et al. 2015). These are also considered as semiquantitative indicators for changes in the PSI content of a leaf. The DF has been reported to decrease under stress conditions (Zhang and Xing 2008). $I_{1} / I_{2}$ is inversely related to electron flow in PSII and was reported to be sensitive to mild stress (Goltsev et al. 2012). The $\mathrm{I}_{1} / \mathrm{I}_{2}$ indicated the improved electron flow in PSII in tobacco grown under $5 \%$ PEG and $0.1 \mathrm{M} \mathrm{NaCl}$ stress. The $\mathrm{I}_{4} / \mathrm{D}_{2}$, an indicator of transmembrane proton gradient (Goltsev et al. 2005, Salvatori et al. 2014), showed reduced proton gradient under stressed conditions. The present results clearly indicated the reduced biophysical performance of the photosynthetic system in tobacco under stress.

In the present study, the results obtained with gas exchange, modulated fluorescence, and multisignal fluorescence measurements were found co-related with each other. The reduced ETR and electron fluxes under stress conditions indicated impairment in electron transfer which ultimately resulted in lower $\Phi_{\mathrm{PSII}}, \mathrm{CO}_{2}$ fixation, and performance indexes in tobacco. In consonance with these results, van Heerden et al. (2007) reported a good correlation of declining $\mathrm{CO}_{2}$ assimilation capacity with declining $\mathrm{PI}_{\mathrm{abs}}$.

Conclusion: Drought and salt stress significantly influenced photosynthesis and PSII efficiency in tobacco plants. Drought and salt stress caused reduction in maximum carboxylation rate, RuBP regeneration, triose-phosphate utilization, and mesophyll conductance along with an increase in heat dissipation and day respiration. The increased day respiration supported the supply RuBP for photosynthetic fixation of $\mathrm{CO}_{2}$ under stress conditions. Stress caused a reduction in the size of plastoquinone pool, the activity of the water-splitting complex, and performance index. Stress-induced variations in energy absorption, trapping, and dissipation per reaction center indicated the changes in the architecture of light-harvesting complex. The decreased stomatal conductance, dissipation of trapped energy as heat, impaired electron transfer at the donor side of the PSII causing accumulation of $\mathrm{P}_{680}{ }^{+}$, and changes in the architecture of light-harvesting complex were the principle reasons for the decreased photosynthetic performance under stress conditions.

\section{References}

Ahmad S., Wahid A., Rasul E.: Comparative morphological and physiological responses of green gram genotypes to salinity applied at different growth stages. - Bot. Bull. Acad. Sin. 46: 135-142, 2005.

Ashraf M., Harris P.J.C.: Photosynthesis under stressful environments: an overview. - Photosynthetica 51: 163-190, 2013.

Bussotti F., Desotgiu R., Cascio C. et al.: Ozone stress in woody plants assessed with chlorophyll $a$ fluorescence. A critical reassessment of existing data. - Environ. Exp. Bot. 73: 1930, 2011.

Centritto M., Loreto F., Chartzoulakis K.: The use of low $\left[\mathrm{CO}_{2}\right]$ to estimate diffusional and non-diffusional limitations of photosynthetic capacity of salt- stressed olive saplings. Plant Cell Environ. 26: 585-594, 2003.

Chamovitz D., Sandmann G., Hirschberg J.: Molecular and biochemical characterization of herbicide-resistant mutants of cyanobacteria reveals that phytoene desaturation is a ratelimiting step in carotenoid biosynthesis. - J. Biol. Chem. 268: 17348-17353, 1993.

Choinski Jr J.S., Ralph P., Eamus D.: Changes in photosynthesis during leaf expansion in Corymbia gummifera - Aust. J. Bot. 51: 111-118, 2003.

Dąbrowski P., Baczewska A.H., Pawluśkiewicz B. et al.: Prompt chlorophyll $a$ fluorescence as a rapid tool for diagnostic changes in PSII structure inhibited by salt stress in Perennial ryegrass. - J. Photoch. Photobio. B 157: 22-31, 2016.

Debez A., Koyro H.W., Grignon C. et al.: Relationship between the photosynthetic activity and the performance of Cakile maritima after long-term salt treatment. - Physiol. Plantarum 133: 373-385, 2008.

Demetriou G., Neonaki C., Navakoudis E. et al:: Salt stress impact on the molecular structure and function of the photosynthetic apparatus - the protective role of polyamines. BBA-Bioenergetics 1767: 272-280, 2007.

Dionisio-Sese M.L., Tobita S.: Effects of salinity on sodium content and photosynthetic responses of rice seedlings differing in salt tolerance. - J. Plant Physiol. 157: 54-58, 2000.

Driever S.M., Baker N.R.: The water-water cycle in leaves is not a major alternative electron sink for dissipation of excess excitation energy when $\mathrm{CO}_{2}$ assimilation is restricted. - Plant Cell Environ. 34: 837-846, 2011.

Evans E.H., Crofts, A.R.: The relationship between delayed fluorescence and the $\mathrm{H}^{+}$gradient in chloroplasts. - BBABioenergetics 292: 130-139, 1973.

Flexas J., Bota J., Loreto F. et al.: Diffusive and metabolic limitations to photosynthesis under drought and salinity in $\mathrm{C}_{3}$ plants. - Plant Biol. 6: 269-279, 2004.

Foyer C.H., Ferrario-Méry S., Huber S.C.: Regulation of carbon fluxes in the cytosol: coordination of sucrose synthesis, nitrate reduction and organic acid and amino acid biosynthesis. In: Leegood R.C., Sharkey T.D., von Caemmerer S. (ed.): Photosynthesis. Advences in Photosynthesis and Respiration. Pp. 177-203. Springer, Dordrecht 2000.

Fusaro L., Gerosa G., Salvatori E. et al.: Early and late adjustments of the photosynthetic traits and stomatal density in Quercus ilex L. grown in an ozone-enriched environment. Plant Biol. 18: 13-21, 2016.

Gao J., Li P.M., Ma F.W., et al.: Photosynthetic performance during leaf expansion in Malus micromalus probed by chlorophyll $a$ fluorescence and modulated $820 \mathrm{~nm}$ reflection. - J. Photoch. Photobio. B 137: 144-150, 2014.

Goltsev V., Chernev P., Zaharieva I. et al.: Kinetics of delayed chlorophyll $a$ fluorescence registered in milliseconds time 
range. - Photosynth. Res. 84: 209-215, 2005.

Goltsev V., Zaharieva I., Chernev P. et al.: Delayed fluorescence in photosynthesis. - Photosynth. Res. 101: 217-232, 2009.

Goltsev V., Zaharieva I., Chernev P. et al.: Drought-induced modifications of photosynthetic electron transport in intact leaves: analysis and use of neural networks as a tool for a rapid non-invasive estimation. - BBA-Bioenergetics 1817: 1490-1498, 2012.

Govindjee: Sixty-three years since kautsky: chlorophylla fluorescence. - Aust. J. Plant Physiol. 22: 131-160, 1995.

Haque Md. I., Rathore Mangal S., Gupta H. et al.: Inorganic solutes contribute more than organic solutes to the osmotic adjustment in Salicornia brachiata (Roxb.) under natural saline conditions. - Aquat. Bot. 142: 78-86, 2017.

Huang W., Zhang S.B., Hu H.: Sun leaves up-regulate the photorespiratory pathway to maintain a high rate of $\mathrm{CO}_{2}$ assimilation in tobacco. - Front. Plant Sci. 5: 688, 2014.

Inskeep W.P., Bloom P.R.: Extinction coefficients of chlorophyll $a$ and $b$ in N,N-dimethylformamide and $80 \%$ acetone. - Plant Physiol. 77: 483-485, 1985.

Jafarinia M., Shariati M.: Effects of salt stress on photosystem II of canola plant (Brassica napus, L.) probing by chlorophyll a fluorescence measurements. - Iran. J. Sci. Technol. 36: 71, 2012.

Kalaji H.M., Govindjee, Bosa K. et al.: Effects of salt stress on photosystem II efficiency and $\mathrm{CO}_{2}$ assimilation of two Syrian barley landraces. - Environ. Exp. Bot. 73: 64-72, 2011.

Kalaji H.M., Goltsev V., Bosa K. et al.: Experimental in vivo measurements of light emission in plants: a perspective dedicated to David Walker. - Photosynth. Res. 114: 69-96, 2012.

Kalaji H.M., Jajoo A., Oukarroum A. et al.: Chlorophyll a fluorescence as a tool to monitor physiological status of plants under abiotic stress conditions. - Acta Physiol. Plant. 38: 102, 2016.

Kalaji H.M., Schansker G., Ladle R.J. et al.: Frequently asked questions about in vivo chlorophyll fluorescence: practical issues. - Photosynth. Res. 122: 121-158, 2014.

Kan X., Ren J.J., Chen T.T. et al.: Effects of salinity on photosynthesis in maize probed by prompt fluorescence, delayed fluorescence and P700 signals. - Environ. Exp. Bot. 140: 56-64, 2017.

Krasteva V., Alexandrov V., Chepisheva M. et al.: Drought induced damages of photosynthesis in bean and plantain plants analyzed in vivo by chlorophyll $a$ fluorescence. - Bulg. J. Plant Physiol. 19: 39-44, 2013.

Krüger G.H.J., De Villiers M.F., Strauss A.J. et al.: Inhibition of photosystem II activities in soybean (Glycine max) genotypes differing in chilling sensitivity. - S. Afr. J. Bot. 95: 85-96, 2014.

Kumari J., Udawat P., Dubey A.K. et al.: Overexpression of SbSI-1, a nuclear protein from Salicornia brachiata confers drought and salt stress tolerance in tobacco by curtailing oxidative damage and maintaining photosynthetic efficiency. - Front. Plant Sci. 8: 1215, 2017.

Lawlor D.W.: Limitation to photosynthesis in water-stressed leaves: stomata $v s$. metabolism and the role of ATP. - Ann. Bot.-London 89: 871-885, 2002.

Lazár D.: Parameters of photosynthetic energy partitioning. - J. Plant Physiol. 175: 131-147, 2015.

Lee B.R., Zaman R., Avice J.C. et al.: Sulfur use efficiency is a significant determinant of drought stress tolerance in relation to photosynthetic activity in Brassica napus cultivars. - Front. Plant Sci. 7: 459, 2016.

Loreto F., Centritto M., Chartzoulakis K.: Photosynthetic limitations in olive cultivars with different sensitivity to salt stress. - Plant Cell Environ. 26: 595-601, 2003.

Maroco J.P., Rodrigues M.L., Lopes C. et al.: Limitations to leaf photosynthesis in field-grown grapevine under droughtmetabolic and modelling approaches. - Funct. Plant Biol. 29: 451-459, 2002.

Mathur S., Mehta P., Jajoo A.: Effects of dual stress (high salt and high temperature) on the photochemical efficiency of wheat leaves (Triticum aestivum). - Physiol. Mol. Biol. Plant. 19: 179-188, 2013.

Maxwell K., Johnson G.N.: Chlorophyll fluorescence - a practical guide. - J. Exp. Bot. 51: 659-668, 2000.

Mehta P., Jajoo A., Mathur S. et al.: Chlorophyll a fluorescence study revealing effects of high salt stress on photosystem II in wheat leaves. - Plant Physiol. Bioch. 48: 16-20, 2010.

Misra A.N., Srivastava A., Strasser R.J.: Utilization of fast chlorophyll a fluorescence technique in assessing the salt/ion sensitivity of mung bean and Brassica seedlings. - J. Plant Physiol. 158: 1173-1181, 2001.

Miyake C., Horiguchi S., Makino A. et al.: Effects of light intensity on cyclic electron flow around PSI and its relationship to nonphotochemical quenching of $\mathrm{Chl}$ fluorescence in tobacco leaves. - Plant Cell Physiol. 46: 1819-1830, 2005.

Moradi F., Ismail A.M.: Responses of photosynthesis, chlorophyll fluorescence and ROS-scavenging systems to salt stress during seedling and reproductive stages in rice. - Ann. Bot.London 99: 1161-1173, 2007.

Murashige T., Skoog F.: A revised medium for rapid growth and bio assays with tobacco tissue cultures. - Physiol. Plantarum 15: 473-497, 1962.

Netondo G.W., Onyango J.C., Beck E.: Sorghum and salinity. Crop Sci. 44: 797-805, 2004.

Oukarroum A., Bussotti F., Goltsev V., Kalaji H.M.: Correlation between reactive oxygen species production and photochemistry of photosystems I and II in Lemna gibba L. plants under salt stress. - Environ. Exp. Bot. 109: 80-88, 2015.

Oukarroum A., El Madidi S., Strasser R.J.: Differential heat sensitivity index in barley cultivars (Hordeum vulgare L.) monitored by chlorophyll $a$ fluorescence OKJIP. - Plant Physiol. Bioch. 105: 102-108, 2016.

Oukarroum A., Goltsev V., Strasser R.J.: Temperature effects on pea plants probed by simultaneous measurements of the kinetics of prompt fluorescence, delayed fluorescence and modulated $820 \mathrm{~nm}$ reflection. - PLoS ONE 8: e59433, 2013.

Oukarroum A., Schansker G., Strasser R.J.: Drought stress effects on photosystem I content and photosystem II thermotolerance analyzed using $\mathrm{Chl} a$ fluorescence kinetics in barley varieties differing in their drought tolerance. - Physiol. Plantarum 137: 188-199, 2009.

Pereira W.E., de Siqueira D.L., Martínez C.A. et al.: Gas exchange and chlorophyll fluorescence in four citrus rootstocks under aluminium stress. - J. Plant Physiol. 157: 513-520, 2000.

Pérez-López U., Robredo A., Lacuesta M. et al:: Elevated $\mathrm{CO}_{2}$ reduces stomatal and metabolic limitations on photosynthesis caused by salinity in Hordeum vulgare. - Photosynth. Res. 111: 269-283, 2012.

Ranjbarfordoei A., Samson R., Van Damme P.: Chlorophyll fluorescence performance of sweet almond [Prunus dulcis (Miller) D. Webb] in response to salinity stress induced by NaCl. - Photosynthetica 44: 513-522, 2006.

Redondo-Gómez S., Wharmby C., Castillo J.M. et al.: Growth and photosynthetic responses to salinity in an extreme halophyte, Sarcocornia fruticosa. - Physiol. Plantarum 128: 116-124, 2006.

Salvatori E., Fusaro L., Gottardini E. et al.: Plant stress analysis: Application of prompt, delayed chlorophyll fluorescence and $820 \mathrm{~nm}$ modulated reflectance. Insights from independent 
experiments. - Plant Physiol. Bioch. 85: 105-113, 2014.

Salvatori E., Fusaro L., Strasser R.J. et al.: Effects of acute $\mathrm{O}_{3}$ stress on PSII and PSI photochemistry of sensitive and resistant snap bean genotypes (Phaseolus vulgaris L.), probed by prompt chlorophyll " $a$ " fluorescence and $820 \mathrm{~nm}$ modulated reflectance. - Plant Physiol. Bioch. 97: 368-377, 2015.

Santos C.V.: Regulation of chlorophyll biosynthesis and degradation by salt stress in sunflower leaves. - Sci. Hortic.Amsterdam 103: 93-99, 2004.

Schansker G., Tóth S.Z., Strasser R.J.: Methylviologen and dibromothymoquinone treatments of pea leaves reveal the role of photosystem I in the $\mathrm{Chl} a$ fluorescence rise OJIP. BBA-Bioenergetics 1706: 250-261, 2005.

Sharkey T.D.: What gas exchange data can tell us about photosynthesis. - Plant Cell Environ. 39: 1161-1163, 2016.

Sharkey T.D., Bernacchi C.J., Farquhar G.D. et al.: Fitting photosynthetic carbon dioxide response curves for $\mathrm{C} 3$ leaves. - Plant Cell Environ. 30: 1035-1040, 2007.

Strasser R.J., Tsimilli-Michael M., Alaka S.: Analysis of the fluorescence transient. - In: Papageorgiou G.C., Govindjee (ed.): Chlorophyll $a$ Fluorescence: a Signature of Photosynthesis. Pp. 321-362. Springer, Dordrecht 2004.

Strasser R.J., Tsimilli-Michael M., Qiang S. et al.: Simultaneous in vivo recording of prompt and delayed fluorescence and 820 -nm reflection changes during drying and after rehydration of the resurrection plant Haberlea rhodopensis. - BBA-
Bioenergetics 1797: 1313-1326, 2010.

Thomas F.M., Gausling T.: Morphological and physiological responses of oak seedlings (Quercus petraea and Q. robur) to moderate drought. - Ann. Forest Sci. 57: 325-333, 2000.

van Heerden P.D.R., Swanepoel J.W., Krüger G.H.J.: Modulation of photosynthesis by drought in two desert scrub species exhibiting $\mathrm{C}_{3}$-mode $\mathrm{CO}_{2}$ assimilation. - Environ. Exp. Bot. 61: 124-136, 2007.

Wilson K.B., Baldocchi D.D., Hanson P.J.: Spatial and seasonal variability of photosynthetic parameters and their relationship to leaf nitrogen in a deciduous forest. - Tree Physiol. 20: 565578, 2000.

Yamori W., Evans J.R., von Caemmerer S.: Effects of growth and measurement light intensities on temperature dependence of $\mathrm{CO}_{2}$ assimilation rate in tobacco leaves. - Plant Cell Environ. 33: 332-343, 2010.

Yang C., Zhang Z.S., Gao H.Y., et al.: The mechanism by which $\mathrm{NaCl}$ treatment alleviates PSI photoinhibition under chillinglight treatment. - J. Photoch. Photobio. B 140: 286-291, 2014.

Zhang L., Xing D.: Rapid determination of the damage to photosynthesis caused by salt and osmotic stresses using delayed fluorescence of chloroplasts. - Photochem. Photobio. Sci. 7: 352-360, 2008.

Zivcak M., Brestic M., Balatova Z. et al.: Photosynthetic electron transport and specific photoprotective responses in wheat leaves under drought stress. - Photosynth. Res. 117: 529-546, 2013.

(C) The authors. This is an open access article distributed under the terms of the Creative Commons BY-NC-ND Licence. 